\title{
THE ROLE OF THE THYROID GLAND IN EXPERIMENTAL TRAUMATIC SHOCK
}

\author{
By JACK H. OPPENHEIMER,1 HENRY M. WISE, AND DAVID A. LASLEY 2 \\ WITH THE TECH NICAL ASSISTANCE OF HAROLD G. HOLMES \\ (From the Biophysics Division, Directorate of Medical Research, Chemical Warfare Labora- \\ tories, Army Chemical Center, Md.)
}

(Submitted for publication July 16, 1957; accepted October 31, 1957)

Comparatively little attention has been paid to the role of the thyroid gland in shock. Hamolsky, Gierlach, and Jensen (1) demonstrated that the $\mathrm{I}^{131}$ uptake of rats subjected to tourniquet shock was depressed early in shock and that the conversion of radioiodide to the organic form was depressed late in shock. Money (2) showed that bleeding caused a depression in the four hour uptake of $\mathrm{I}^{131}$ in rats.

Because of the meager body of information relating to this problem, it was our purpose to study several aspects of thyroid function in a traumatic shock preparation developed at the Army Chemical Center. This preparation involves the creation of uniformly lethal soft tissue wounds by the detonation of high explosive charges on the hind extremities of Texas Angora goats. Although this method of creating traumatic shock involves multiple variables including blood loss, infection, and soft tissue damage, the clinical picture in the wounded animals is surprisingly uniform and simulates conditions actually prevailing on the battlefield. Additional communications will document the physiological alterations in this preparation and will present evidence that a toxic factor, possibly related to bacterial metabolism, plays a prominent role in the demise of these animals.

In order to assess the changes in thyroidal function in shock, it was thought necessary to explore certain aspects of the normal physiology of the goat thyroid. The interrelationship of thyroid function and traumatic shock were then analyzed by study of : 1) the changes in $\mathrm{I}^{131}$ metabolism induced by shock, and 2) the effect of thyroidal status on the survival of animals subjected to the standard injury.

1 Present address : Department of Medicine, Duke Hospital, Durham, N. C.

2 Present address : Department of Urology, University of Kansas School of Medicine, Kansas City, Kan.

\section{MATERIALS AND METHODS}

The standard preparation. The standard wound shock preparation is described in greater detail elsewhere (3). The animals used were four to five year old castrated male Angora goats weighing between 30 and 50 kilos. Their diet consisted of hay and grain supplement with plentiful rations of salt. The animals were wounded by detonating standard tetryl (a high explosive) pellets on predetermined sites on both thighs of the animals. Hemostasis was effected within minutes after injury by the clamping of bleeding vessels. The external blood loss varied between 50 and $450 \mathrm{ml}$., but in this range the survival time of the animal bore no relation to the amount of bleeding. In this series of experiments, the mean survival time of untreated animals not subjected to experimental manipulation was 22.6 hours and the standard deviation plus or minus 4.6 hours.

Isotopic methods. All animals used in the isotopic studies received approximately $10 \mu \mathrm{c}$. carrier-free $\mathrm{I}^{132}$, as $\mathrm{NaI}$, by intravenous injection into the external jugular vein. Measurements of neck activity and that of the excised thyroid glands were made with a collimated probe (Nuclear-Chicago, Model DS-1) bearing a threefourths inch $\mathrm{NaI}$ scintillation crystal. Liquid samples $(2 \mathrm{ml}$.) were placed into a well-type counter (NuclearChicago). All counts were recorded by a binary scaling unit (Nuclear-Chicago, Model 183). All in vitro counts were performed with a counting error no greater than plus or minus 5 per cent. The stability of the counting circuits was checked daily against a standard source of $\mathrm{Cs}^{137}$. Appropriate corrections for physical decay of $\mathrm{I}^{181}$ and for background activity were made.

Thyroidal uptake of $I^{181}$. In the 11 day uptake experiments, the animals were mounted on carts for a period of time sufficient for the required measurements. After the completion of the test, they were released into their stalls until the next determination. The total neck activity was determined by placing the probe $20 \mathrm{~cm}$. from the geometrical center of the thyroid, as estimated by anatomical landmarks. In order to assess the nonthyroidal contribution to the total count thus determined, a curved lead shield ( $3 / 4 \times 6 \times 8$ inches) was placed over the thyroid and the measurement repeated. The difference in the two determinations was shown to represent a reasonable approximation of the thyroidal component of the total activity "seen" by the probe. Since it was desirable to convert serial determinations expressed in counts per minute into per cent of dose ad- 
ministered, the animal was sacrificed at the end of the experiment, the thyroid excised and compared directly in activity to an aliquot of the original dose. The following relationship was then applied to convert individual readings into per cent:

$$
P_{t}=\frac{P_{\text {terminal }}}{C_{\text {terminal }}} \times C_{t},
$$

where $P_{t}$ equals uptake at time $t$, expressed as per cent of dose; $\mathrm{P}_{\text {terminal }}$ equals uptake of excised thyroid, as per cent of dose; and $\mathrm{C}_{\text {terminal }}$ equals uptake, in counts per minute, just before sacrificing the animal and excising thyroid.

Effect of traumatic shock on iodide metabolism. The dynamics of iodide metabolism were studied in 10 control animals and in 11 animals subjected to the standard injury, for a period of 6 hours following the injection of a $10 \mu \mathrm{c}$. dose of $\mathrm{I}^{121}$. The isotope was administered to the experimental animals within one-half hour after injury. The following determinations were made in each case: a) the 6 hour thyroidal uptake, b) the 6 hour renal excretion, and c) plasma $\mathrm{I}^{181}$ concentration at 5, 10, 20 and 30 minutes and 1, 2, 3, 4, 5 and 6 hours after administration of the dose.

Since injured animals in the standard preparation were immobilized on carts, it was felt desirable to keep control animals in a similar position in order to insure the uniformity of experimental conditions. Other experiments in this series had shown that the glomerular filtration rate drops sharply after the animal is mounted on the cart but returns to normal values within 24 hours in the restrained prone position. For this reason, all animals employed in these experiments were placed on the carts and catheterized externally one day prior to the experiment.

At the end of the six hour period each animal was sacrificed, the thyroid excised, and the uptake directly obtained by comparing the in vitro count to that of an aliquot of the administered dose. This method allowed precise measurements of even small percentage uptakes of $\mathrm{I}^{132}$.

The volume of urine excreted in the course of the experiment was measured by pooling the urine voided through an external catheter and the bladder urine aspirated at the end of the six hour period. The activity of a $2 \mathrm{ml}$. sample of this pooled urine was compared to that of a known dilution of the original dose, and the per cent of the dose excreted computed on the basis of the known volume of urine formed. The values for urinary excretion were not as reliable as those for thyroidal uptake since the loss of small quantities of urine during the manipulation frequently occurred. This introduced a systematic error into the values dependent on urinary excretion. It was felt that the error thus introduced was not sufficiently great to negate the validity of the trends observed in these experiments. The use of indwelling bladder catheters, while ideally desirable, was not technically satisfactory.

At the above designated intervals, $10 \mathrm{ml}$. samples of blood were withdrawn from an external jugular vein catheter into heparinized syringes. Two ml. plasma samples were separated from the supernatant of the centrifuged specimens, and the activity compared to that of a known dilution of the original dose. No detectable quantities of protein-bound $\mathrm{I}^{131}$ (presumably hormonal $\mathrm{I}^{181}$ ) were found in the period under consideration.

On the basis of the above determinations, the following values were computed: a) renal and thyroidal clearance of $\left.\mathrm{I}^{131}, \mathrm{~b}\right)$ the volume of $\mathrm{I}^{131}$ distribution at five minutes and six hours, and c) the mean plasma concentration.

Renal and thyroidal plasma clearance may be defined by the expression:

$$
K=\frac{I_{t}}{\int_{0}^{t} c d t} \times 1,000,
$$

where $\mathrm{K}$ equals renal or thyroidal clearance ( $\mathrm{ml}$. per minute), $I_{t}$ equals $I^{131}$ taken up by thyroid or excreted by kidney in time $t$ (per cent dose), $c$ equals instantaneous plasma concentration of $\mathrm{I}^{131}$ (per cent dose per liter), $t$ equals time in minutes, and 1,000 equals conversion factor from liters to $\mathrm{ml}$. The function $\int_{0}^{t} \mathrm{cdt}$ was obtained graphically from a curve through points representing a plot of plasma concentration as a function of time. Clearance values were normalized to body surface by applying the formula SA minus $\mathrm{KW}^{2 / 3}$ where SA equals surface area $\left(\mathrm{M}^{2}\right), \mathrm{W}$ equals body weight $(\mathrm{Kg}$.$) , and \mathrm{K}$ equals 0.83 , as obtained by Ritzman and Colovos (4). While clearance may well be considered a constant in normal animals in stable iodine equilibrium $(5,6)$, in the case of traumatized animals this function, as determined in these experiments, must be regarded as an average value over the time interval studied, since one can no longer assume stable iodine equilibrium.

The volume of $\mathrm{I}^{131}$ distribution is obtained by dividing the dose of radioiodide retained by the body by the simultaneous plasma concentration. In the case of the five minute determination, the amount of iodide excreted in the urine and taken up in the thyroid can be neglected and the space of distribution will thus be $\frac{100}{c}$. At the end of six hours, the space can be computed by the expression $\frac{100-(U+R)}{c}$, where $c$ is defined above, and $U$ and $\mathrm{R}$ represent the six hour thyroidal uptake and renal excretion, respectively, expressed in per cent dose. The mean plasma concentration is defined as the expression $\int_{0}^{t}$ $\frac{\int_{0}^{t} \mathrm{cdt}}{t}$, expressed in per cent dose per liter. The methodological considerations here employed are based upon previous analyses by Berson, Yalow, Sorrentino, and Roswit (6), Keating, Wang, Luellen, Williams, Power, and $\mathrm{McC}$ Conahey (7), and Ingbar (8).

Protein-bound iodine (PBI) determinations. ${ }^{3}$ A modi-

3 We are indebted to Lt. Colonel Thomas Jeffris, Commanding Officer, Second Army Area Medical Laboratory, Fort George Meade, Md., for allowing us the use of his facilities in the performance of the PBI determina- 


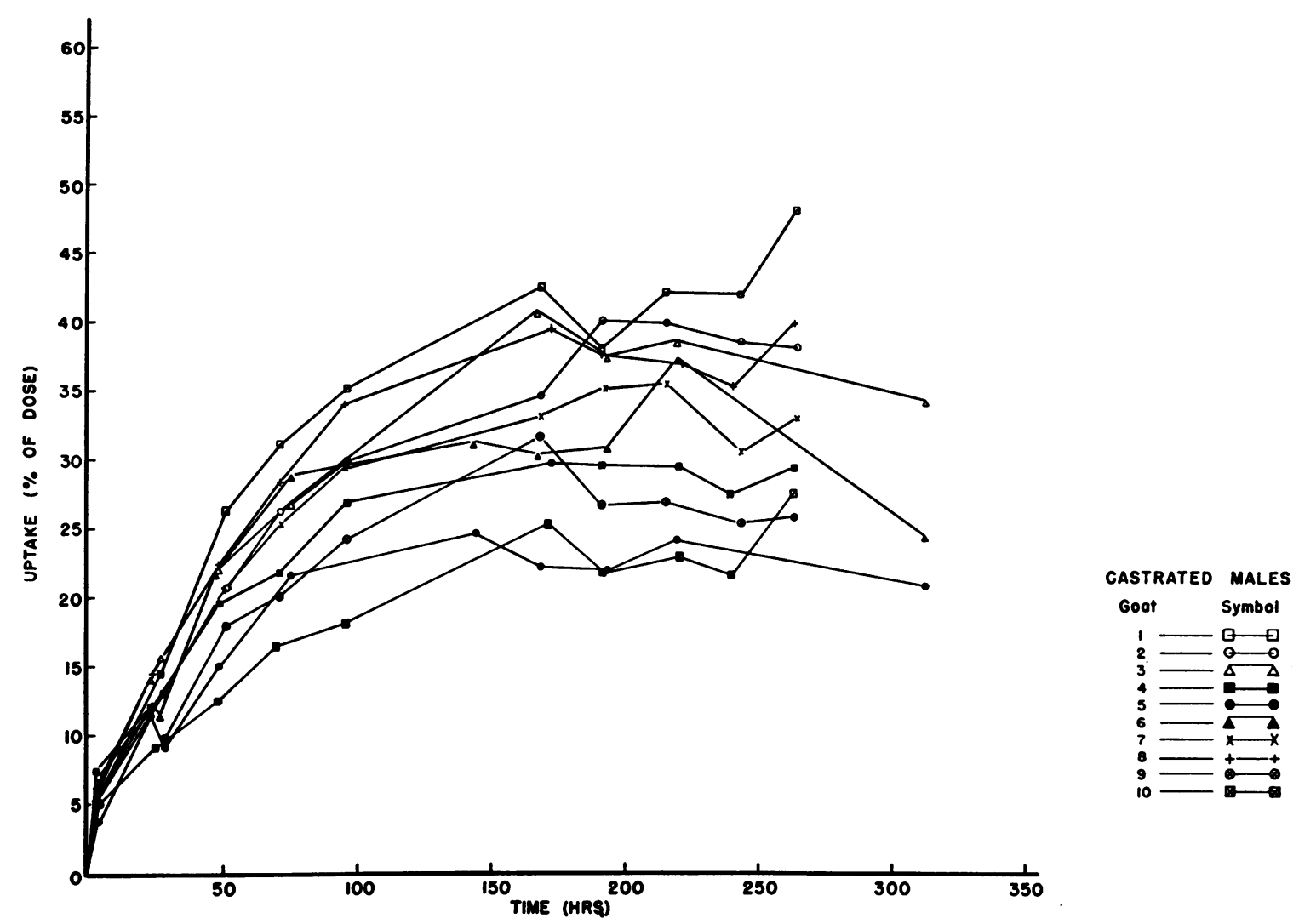

Fig. 1. Thyroidal I In Uptake of Ten Goats

Goats 1 to 10 are a different set of animals from those similarly numbered in Table $\mathrm{I}$.

fication of Barker's dry ashing technique (9) was employed for the determination of protein-bound stable iodine.

Statistical methods. ${ }^{3}$ The " $\mathrm{t}$ " test was employed in all statistical treatments except in the analysis of the data contained in the section on the effect of thyroidal status on survival time. Here, the analysis of variance was employed to evaluate the statistical interrelationship of the groups involved.

\section{RESULTS}

I. Some aspects of normal thyroidal metabolism of the goat

$A$. Uptake of $I^{131}$. The results of uptakes performed on 10 castrated goats are indicated in Figure 1. Maximal uptake values varied from approximately 20 to 40 per cent of the administered dose but were not reached until about 170 hours

tions. We also acknowledge the assistance of $\mathrm{Mr}$. G. Stanley Woodson, of the Biostatistics Section, Wound Assessment Branch, Biophysics Division, Chemical Warfare Laboratories, Army Chemical Center, Md., in the statistical evaluations of our data. after the injection. The nature of these curves was not related to possible metabolic derangements secondary to castration, since entirely comparable curves were plotted in five uncastrated males and five females of the same strain.

A curve representing the mean of all determinations on the 10 castrated goats is represented in the upper portion of Figure 2. In the lower half of this figure the difference between the mean maximal uptake $\left(U_{\max }\right)$ and the mean uptake at time $t(U)$ was plotted as a function of $t$ on a semilogarithmic scale. This function approximated a straight line. The straight line relationship also held true for individual animals. It has been shown (6) that the function $U_{\max }$ minus $U$ is directly related to the dose of $\mathrm{I}^{131}$ retained in the iodide space at any instant. The straight line relationship would then imply an exponential decrease in retained $\mathrm{I}^{131}$ over a large portion of the time interval considered.

$B$. Thyroidal and renal clearance. The mean thyroidal clearance was determined to be $2.29 \mathrm{ml}$. 
per minute per $\mathrm{M}^{2}{ }^{2}$, and the renal clearance 3.32 ml. per minute per M. ${ }^{2}$ (Table I). If one assumes that radioiodide is distributed quantitatively to the thyroid and the kidney and if one discounts the small amounts of $\mathrm{I}^{131}$ liberated as hormonal $\mathrm{I}^{131}$, it can be shown that $U_{\max }=\frac{k_{u}}{k_{r}+k_{u}}$, where $U_{\max }$ is the maximal thyroidal uptake, $k_{u}$ is thyroidal clearance, and $k_{r}$ is renal clearance. $U_{\max }$ thus calculated for the average of the 10 animals in which clearances were determined was 41 per cent. This figure may be somewhat high, since, as previ- ously mentioned, the renal clearances may have been underestimated.

C. Iodide space. The iodide ${ }^{131}$ space determined five minutes after the injection of the dose was 7.72 liters or 21 per cent body weight, and it expanded to 26.51 liters or 73 per cent body weight at the end of six hours (Table I).

D. $P B I$ values. The $\mathrm{PBI}$ values of 73 normal goats were determined. The mean PBI was 6.06 $\mu \mathrm{g}$. per $100 \mathrm{ml}$. serum with a standard deviation of plus or minus 1.30 .

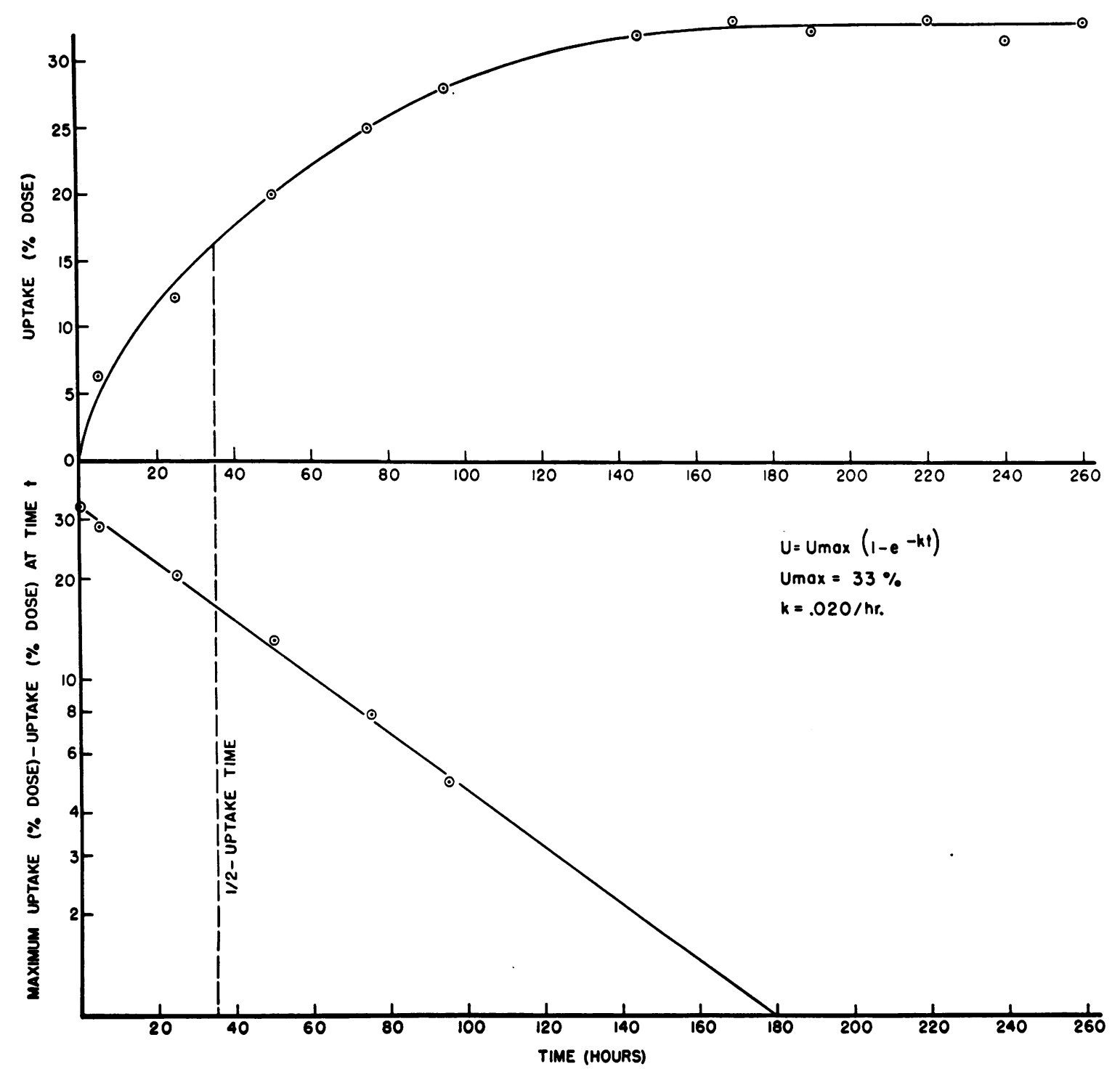

Fig. 2. The Average of Values Indicated in Figure 1 (Upper Half) and Umax Minus U as a Function of Time (Semi-Log Plot, Lower Half)

The broken line is drawn at the time coordinate of one-half $U_{\max }$. 
TABLE I

Iodide metabolism in normal and injured goats

\begin{tabular}{|c|c|c|c|c|c|c|c|c|c|}
\hline \multirow{2}{*}{\multicolumn{2}{|c|}{ Goat no. }} & \multirow[b]{2}{*}{ Weight } & \multirow{2}{*}{$\begin{array}{c}\text { Average } \\
\text { plasma } \\
\text { concentration }\end{array}$} & \multicolumn{2}{|c|}{ Iodide space } & \multicolumn{2}{|c|}{ Thyroidal } & \multicolumn{2}{|c|}{ Renal } \\
\hline & & & & $5 \mathrm{~min}$. & $6 \mathrm{hrs}$. & Uptake & Clearance & Excretion & Clearance \\
\hline $\begin{array}{l}\bar{\varpi} \\
\text { हू } \\
\text { Z }\end{array}$ & $\begin{array}{r}1 \\
2 \\
3 \\
4 \\
5 \\
6 \\
7 \\
8 \\
9 \\
10\end{array}$ & $\begin{array}{c}K g . \\
37 \\
38 \\
32 \\
35 \\
37 \\
38 \\
35 \\
35 \\
37 \\
39\end{array}$ & $\begin{array}{c}\text { \% dose/L. } \\
4.10 \\
4.81 \\
6.65 \\
6.54 \\
4.53 \\
4.96 \\
4.52 \\
5.79 \\
5.74 \\
4.28\end{array}$ & $\begin{array}{c}L . \\
9.08 \\
8.75 \\
6.43 \\
6.16 \\
8.08 \\
9.29 \\
7.85 \\
7.10 \\
5.88 \\
8.55\end{array}$ & $\begin{array}{c}L . \\
34.60 \\
30.37 \\
18.47 \\
20.44 \\
28.24 \\
24.56 \\
36.22 \\
22.82 \\
19.84 \\
29.49\end{array}$ & $\begin{array}{c}\text { \% dose } \\
2.74 \\
1.66 \\
2.86 \\
2.85 \\
8.61 \\
4.83 \\
4.15 \\
1.76 \\
2.78 \\
4.70\end{array}$ & $\begin{array}{c}\text { ml. } / \text { min./M.2 } \\
2.02 \\
1.02 \\
1.43 \\
1.36 \\
5.73 \\
2.89 \\
2.87 \\
0.95 \\
1.45 \\
3.20\end{array}$ & $\begin{array}{c}\text { \% dose } \\
5.91 \\
1.75 \\
7.57 \\
5.97 \\
4.40 \\
5.28 \\
6.38 \\
5.59 \\
6.92 \\
5.64\end{array}$ & $\begin{array}{c}\text { ml. } / \min . / M .{ }^{2} \\
4.35 \\
1.08 \\
3.81 \\
2.84 \\
2.93 \\
3.16 \\
4.41 \\
3.02 \\
3.73 \\
3.84\end{array}$ \\
\hline & Mean \pm S.D. & $36.3 \pm 2.0$ & $5.19 \pm 0.93$ & $7.72 \pm 1.25$ & $26.51 \pm 6.23$ & $3.69 \pm 2.05$ & $2.29 \pm 1.46$ & $5.54 \pm 1.59$ & $3.32 \pm 0.97$ \\
\hline 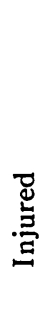 & $\begin{array}{l}11 \\
12^{*} \\
13 \\
14 \\
15 \\
16 \\
17 \\
18 \\
19 \\
20 \\
21 \ddagger\end{array}$ & $\begin{array}{l}36 \\
35 \\
36 \\
37 \\
39 \\
33 \\
33 \\
35 \\
33 \\
35 \\
36\end{array}$ & $\begin{array}{c}5.94 \\
8.17 * \\
7.60 \\
7.00 \\
5.80 \\
10.01 \\
8.28 \\
6.87 \\
7.35 \\
8.06 \\
6.83 \ddagger\end{array}$ & $\begin{array}{l}6.01 \\
5.38 \\
4.49 \\
4.68 \\
6.57 \\
3.94 \\
4.46 \\
4.91 \\
5.17 \\
5.34 \\
5.88\end{array}$ & $\begin{array}{l}19.80 \\
\\
17.28 \\
22.58 \\
21.47 \\
\dagger \\
13.76 \\
20.35 \\
18.29 \\
16.42 \\
17.58\end{array}$ & $\begin{array}{l}1.30 \\
1.31^{*} \\
1.36 \\
1.10 \\
0.89 \\
1.00 \\
1.62 \\
1.29 \\
1.27 \\
1.74 \\
7.06 \ddagger\end{array}$ & $\begin{array}{l}0.67 \\
0.64 \\
0.55 \\
0.47 \\
0.45 \\
0.33 \\
0.64 \\
0.59 \\
0.56 \\
0.68 \\
3.19 \ddagger\end{array}$ & $\begin{array}{l}6.62 \\
3.84^{*} \\
2.24 \\
2.03 \\
0.99 \\
\dagger \\
2.07 \\
1.05 \\
2.20 \\
4.32 \\
2.76 \ddagger\end{array}$ & $\begin{array}{l}3.40 \\
2.14 \\
0.91 \\
0.87 \\
0.45 \\
\dagger \\
0.81 \\
0.48 \\
0.97 \\
1.68 \\
1.24\end{array}$ \\
\hline & Mean \pm S.D. & $35.3 \pm 1.8$ & $7.43 \pm 1.28$ & $5.17 \pm 0.76$ & $18.61 \pm 2.73$ & $1.28 \pm 0.27$ & $0.56 \pm 0.11$ & $2.69 \pm 1.87$ & $1.30 \pm 0.96$ \\
\hline & $\mathrm{p} \S$ & 0.3 & 0.001 & 0.001 & 0.01 & 0.01 & 0.01 & 0.01 & 0.001 \\
\hline
\end{tabular}

* Animal 12 died 4 hours after injection. Values marked *, obviously related to decreased survival, are omitted from statistical analysis.

$\dagger$ Technical difficulty in urine collection.

$\ddagger$ Animal 21 was shown to have pathological thyroid (see text). Values marked $\ddagger$, obviously related to increased thyroidal activity, are omitted from statistical analysis.

$\S$ Significance of difference of means of control and experimental series.

\section{The effect of traumatic shock on $I^{181}$ metabo- lism}

It can be seen that thyroidal uptake, thyroidal clearance, renal excretion and renal clearance were all significantly depressed in goats subjected to the standard trauma (Table I). Note should be taken of Goat No. 21 in the experimental group. The thyroidal uptake of this animal was 7.06 per cent in six hours, a value over four times as great as any other uptake in the series. Histological examination showed a picture of intense hyperplasia which fitted into a pathological category noted in occasional goats autopsied by Light (10). For these reasons values directly dependent on increased thyroidal activity were discarded in the statistical evaluation of the results. Goat No. 12 died four hours after injection of the dose. All values for this animal listed in Table II are computed on a four hour instead of a six hour basis. Those values influenced by decreased survival (thyroidal uptake, renal excretion, mean plasma concentration) are also discarded from statistical consideration.

Thyroidal uptake and clearance were apparently depressed to a greater extent from their normal values than were renal excretion and clearance. In both instances, the uptake values were depressed less than the corresponding clearance values because of the concomitant elevation of the plasma concentration of $\mathrm{I}^{131}$ resulting both from the diminished clearances and the reduction of $\mathrm{I}^{181}$ space. Both at five minutes and six hours the $I^{181}$ space was measured to be approximately 70 per cent of normal.

In a series of four animals, goats were allowed to concentrate maximal amounts of $\mathrm{I}^{181}$ in their thyroid glands. One hundred ninety-two hours after the administration of the dose, two animals 
were injured in the standard manner on both hind extremities, and two animals were injured on one side alone, in order to insure longer survival. Serial determinations of neck activity were performed before and after injury, the counts being converted to per cent of dose by making the appropriate comparison to the post mortem in vitro count, as previously described. Examination of the results shows no startling change in the thyroidal content of $\mathrm{I}^{\mathbf{1 8 1}}$ (Figure 3 ). There was some suggestion of a brief drop in Goat No. 9,487, but even this was probably within experimental error. It should be borne in mind that if the rate of turnover of hormone in the goat thyroid is at all comparable to that of the human being, only massive increases in rate of hormone discharge would have resulted in a noticeable change in our determinations.

\section{Effect of thyroidal status on the survival of goats subjected to traumatic shock (Table II)}

In the following group of experiments, the survival times of goats in various metabolic states subjected to the standard trauma were evaluated. Groups of untreated goats were injured as simultaneous controls. Since the various control groups showed surprisingly little variation, they were consolidated for statistical analysis into a single group of 45 goats, with a mean survival time of 22.6 hours.

Ten thyroidectomized animals, wounded 10 days after the surgical procedure, showed no sig- nificant difference in survival time from control animals. Their mean PBI value before wounding was $3.26 \mu \mathrm{g}$. per cent, compared to the goat normal of $6.06 \mu \mathrm{g}$. per cent. No significant changes in weight, pulse, respiration and temperature were noted in the interval following thyroidectomy.

Thirteen animals were given 11 daily intramuscular injections of $2 \mathrm{mg}$. L-thyroxin dissolved in $1 / 30 \mathrm{~N} \mathrm{NaOH}$. At the end of this period the animals showed a striking increase in pulse, respiratory rate, temperature and PBI values (16.86 $\mu \mathrm{g}$. per cent). Their mean weight loss during this period was 9.4 per cent body weight. The animals were injured 10 days after the initiation of thyroxin treatment. Survival time was decreased to 11.7 hours following injury, statistically a highly significant effect. The large standard deviation (plus or minus 8.1 hours) was due to one goat which survived for 35 hours. The $\mathrm{NaOH}$ vehicle had no significant effect on survival time.

A further group of survival experiments was performed to assay possible mechanisms of the thyroxin effect. The possibility that the hyperthyroid state might have induced adrenal cortical depletion presented itself. However, cortisone acetate (Merck), administered in daily $100 \mathrm{mg}$. intramuscular doses two days prior to injury and on the day of injury, did not succeed in reversing the thyroxin effect. Cortisone without thyroxin did not affect survival time.

The possibility that the thyroxin effect on survival time was mediated through weight loss was

TABLE II

Effect of thyroidal status and related factors on survival time of animals subjected to the standard trauma

\begin{tabular}{lccccc}
\hline \multicolumn{1}{c}{ Experimental group } & Mean S.T.* & \pm S.D. & nf & Po\& & Pt\| \\
\hline A. Controls & 22.6 & 4.6 & 45 & & 0.01 \\
B. Thyroidectomized & 23.5 & 4.9 & 10 & N.S. & 0.01 \\
C. Thyroxin & 11.7 & 8.1 & 13 & 0.01 & 0.01 \\
D. 1/30 N NaOH (thyroxin vehicle) & 24.9 & 3.0 & 9 & N.S. & N.S. \\
E. Thyroxin plus cortisone & 11.8 & 4.2 & 10 & 0.01 & 0.01 \\
F. Cortisone & 22.7 & 4.3 & 10 & N.S. & 0.05 \\
G. Partial starvation & 18.7 & 4.9 & 10 & N.S. & N.S. \\
H. Maximal starvation & 14.2 & 7.5 & 10 & 0.01 & N.S. \\
I. 2, 4-dinitrophenol & 16.5 & 8.7 & 10 & 0.01 & 0.01 \\
J. Saline (dinitrophenol vehicle) & 21.0 & 9.9 & 9 & N.S. & 0.7 \\
\hline
\end{tabular}

* Survival time.

† Standard deviation.

₹ Number of experimental animals.

Probability that Mean S. T. controls minus Mean S. T. experimental group equals 0.

II Probability that Mean S. T. thyroxin group minus Mean S. T. experimental group equals 0.

I Not significant $(p>0.05)$. All " $p$ " values are less than expressed figure. 


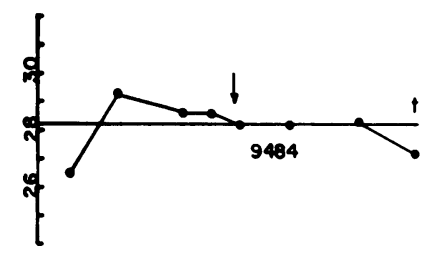

EFFECT OF MASSIVE TRAUMA ON THYROIDAL CONTENT OF 131

T TIME OF DEATH

$\downarrow$ TIME OF MUURY (192 hrs. offer $1^{131}$ injection)

9484\} BILATERAL BLAST

9486\}) UNILATERAL BLAST
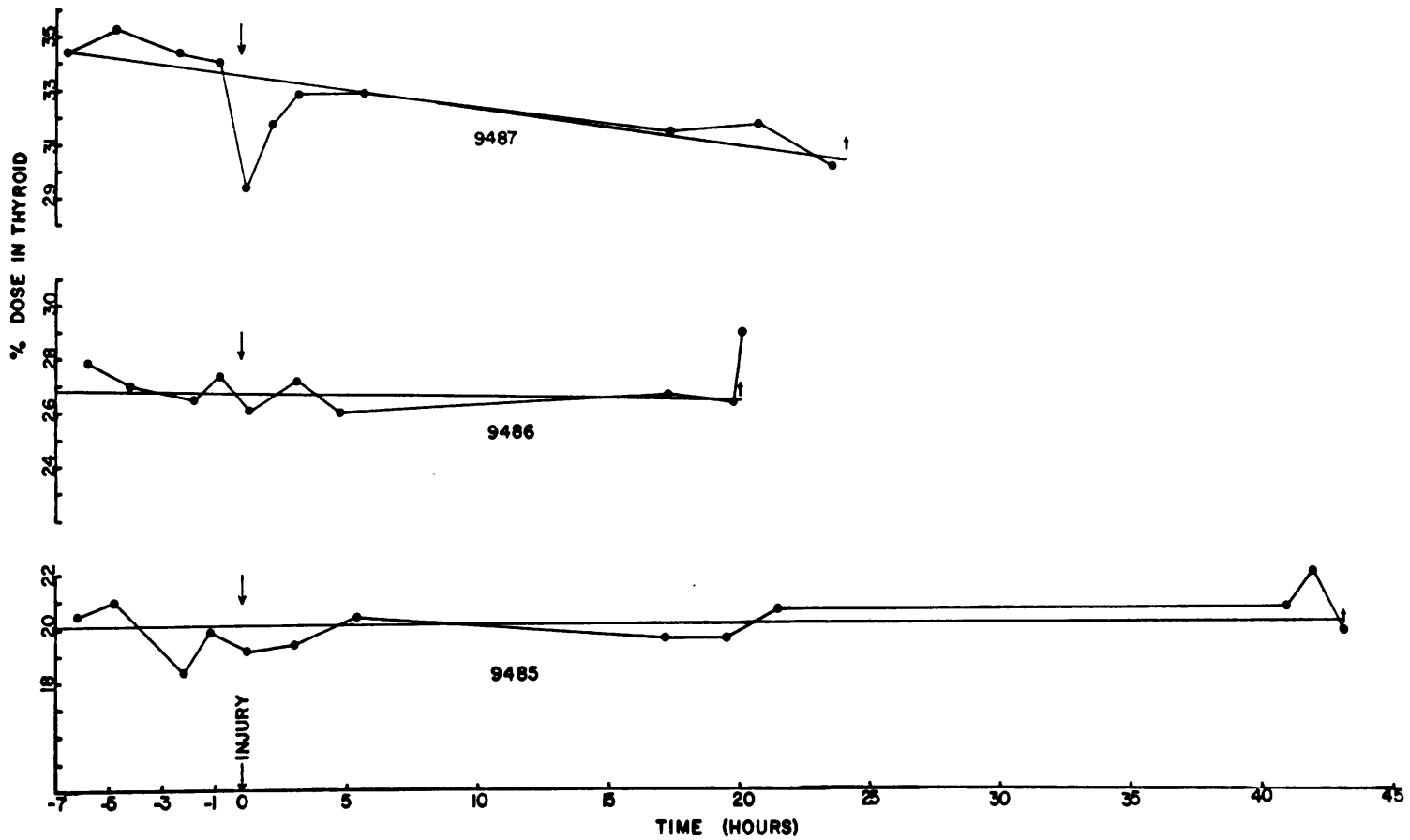

Fig. 3. Effect of Trauma on Thyroidal I ${ }^{131}$ Content

examined. A group of animals were starved to produce a weight loss of 6.3 per cent body weight (the weight loss of the first nine thyroxin-treated animals). While the survival of this group was depressed (18.7 hours), it was still significantly different from the thyroxin group. Because of the difficulty of assessing the true tissue body weight in the goat, since up to 20 per cent of the measured weight may lie in the gastrointestinal system (10), animals were maximally starved for 10 days by withholding food but not water. The survival of this group (14.2 hours) did not differ significantly from the thyroxin group.

The known sensitivity of hyperthyroid animals to anoxia (11) suggested that thyroxin acted similarly in shock, where stagnant and anemic anoxia are operative. For this reason it was thought appropriate to study the effect of another compound which increased oxygen consumption. Two hundred mg. 2,4-dinitrophenol dissolved in $250 \mathrm{ml}$. saline was administered intravenously three hours prior to injury. The animals showed a markedly increased rate of respiration at the end of the three hour period. The survival of this group ( 16.5 hours), while not as low as the thyroxin group, did not differ from it statistically. The saline vehicle had no effect on survival time.

\section{DISCUSSION}

The slow uptake of $\mathrm{I}^{181}$ by the goat is a reflection of the low thyroidal ( $2.3 \mathrm{ml}$. per minute per $\left.\mathrm{M} .^{2}\right)$ and renal (3.3 ml. per minute per $\left.\mathrm{M.}^{2}\right)$ clearances when compared to corresponding values in man $\left(10.2 \mathrm{ml}\right.$. per minute per $\mathrm{M}^{2}$ and $20.6 \mathrm{ml}$. per minute per $\mathrm{M.}^{2}$ ) (6). It is impossible to make any definitive conclusions on the basis of the above data regarding the comparative hormonal production of these species because of the lack of knowledge of serum level of stable iodide in the 
goat. The level of PBI in the goat appeared to be quite similar to accepted values in man (12). The larger iodide space in the goat ( 73 per cent body weight) than in man ( 35 per cent body weight) (13) may possibly be attributed to the extensive gastrointestinal system of the ruminant.

It appears that the iodide concentrating capacity is severely reduced in traumatic shock. It is impossible to say on the basis of the information available whether the reduction in thyroidal clearance is a consequence of decreased blood flow or decreased iodide extraction efficiency, or a combination of the two factors. Furthermore, we cannot assume that the decreased clearance of iodide observed in these experiments reflects a decreased production of hormone, since stable iodine equilibrium conditions may not obtain. However, Harris (14) has presented evidence of decreased hormonal liberation in the rabbit subjected to various stresses, including hemorrhage. Other authors (15-17) have reported a decreased $I^{181}$ uptake in "nonspecific stress." However, it has not been ascertained to what extent this depression is due to increased renal clearance induced by cortisone or to more direct effects on the pituitary-thyroid axis by the adrenal hormones. The relationship between adrenal cortical and thyroidal metabolism has recently been reviewed by Ingbar and Freinkel (18) and Money (2).

Regarding the decreased renal clearance of $\mathrm{I}^{131}$ in the present experiments, this would seem to accompany the decrease in effective renal blood flow and glomerular filtration previously noted in our preparation. Worthy of note is the reduction of iodide space induced by traumatic shock. It seems probable that this is related to alterations in some circulatory factor such as a decreased blood flow to the gastrointestinal tract.

The fact that the thyroidal content of $\mathrm{I}^{131} \mathrm{did}$ not change significantly, at least in three of our four animals, would preclude a massive discharge of labeled hormone from the gland. Since the animals were injured when the uptake curve had reached a flat maximum, the experiment could not easily demonstrate a decreased rate of discharge into the circulation. PBI determinations during shock were made in a preliminary set of experiments, and no significant changes were noted out of proportion to the decrease in protein concentration incidental to hemodilution. However, the accuracy of the method did not allow us to attach a great deal of importance to these observations.

The survival experiments would tend to indicate that the recently thyroidectomized animal can resist injury as well as the normal animal. It is certainly possible that if a longer period between thyroidectomy and injury had been allowed, the tissue changes of hypothyroidism might have influenced the survival time one way or another. Nevertheless, the results do suggest that the thyroid does not play an immediate active role in combating the type of stress studied.

The shortened survival of the hyperthyroid animals is consonant with the clinical observation that hyperthyroid patients present an increased operative risk. The shortened survival does not seem to result from adrenal depletion, although in the absence of information regarding adrenal cortical economy of the hyperthyroid animal in shock, it is difficult to judge whether the dosage of cortisone employed was adequate. The dinitrophenol experiments are compatible with the thesis that the thyroxin effect is related to the increased sensitivity to anoxia in a hypermetabolic animal. Weight loss as a reflection of negative nitrogen balance may be a contributory factor.

The deleterious influence of excess thyroxin combined with the fact that thyroidal clearance of iodine is sharply decreased brings to mind the speculation that traumatic shock induces a shutdown of thyroidal activity as an adaptive mechanism for the conservation of metabolic energy.

\section{SUMMARY}

1. Traumatic shock induced a marked reduction in the thyroidal capacity to concentrate iodide, as measured by thyroidal clearance of $\mathrm{I}^{131}$.

2. Renal clearance of $\mathrm{I}^{131}$ was depressed, along with glomerular filtration rate and renal blood flow.

3. The space of iodide distribution was reduced by traumatic shock when measured for the first six hours following the injection of $\mathrm{I}^{131}$.

4. No significant effect by the standard injury on the content of thyroidal $\mathrm{I}^{131}$ was noted when the animals had accumulated maximal amounts of $\mathrm{I}^{131}$. 
5. Recently thyroidectomized animals showed no change in survival times from control values when subjected to the standard injury. Hyperthyroid goats showed marked sensitivity to traumatic shock, a phenomenon which could not be reversed by the administration of cortisone. Animals treated with 2,4-dinitrophenol showed a decrease in survival time statistically comparable to that induced by thyroxin.

6. Values for the thyroidal and renal clearance of iodide, uptake of $\mathrm{I}^{131}$, iodide space, and level of PBI in normal goats have been ascertained.

\section{ACKNOWLEDGMENTS}

The authors wish to thank Drs. J. E. Rall and F. W. Light for their helpful comments and suggestions, and Miss Sarah Woodruff for her secretarial assistance in the preparation of this manuscript.

\section{REFERENCES}

1. Hamolsky, M. W., Gierlach, Z. S., and Jensen, $H$. Uptake and conversion of radioactive iodide ( $\mathrm{I}^{121}$ ) by the thyroid gland in vivo and in vitro in tourniquet shock in rats. Amer. J. Physiol. 1951, 164, 35.

2. Money, W. L. The interrelation of the thyroid and the adrenals in Brookhaven Symposium in Biology. Upton, New York, Brookhaven National Laboratory, 1955, No. 7, p. 137.

3. Ochsner, E. W., Jr., Jacob, S. W., and Mansberger, A. R. A new preparation for the study of experimental shock from massive wounds: I. Standardization. Surgery, In press.

4. Ritzman, E. G., and Colovos, N. F. Circular 32, University of New Hampshire, College of Agriculture, Agricultural Experimental Station, 1930.

5. Myant, N. B., Pochin, E. E., and Goldie, E. A. G. The plasma iodide clearance rate of the human thyroid. Clin. Sci. 1949, 8, 109.
6. Berson, S. A., Yalow, R. S., Sorrentino, J., and Roswit, B. The determination of thyroidal and renal plasma $I^{121}$ clearance rates as a routine diagnostic test of thyroid dysfunction. J. clin. Invest. 1952, 31, 141.

7. Keating, F. R., Jr., Wang, J. C., Luellen, T. J., Williams, M. M. D., Power, M. H., and McConahey, W. M. The measurement of the iodine-accumulating function of the human thyroid gland. $J$. clin. Invest. 1949, 28, 217.

8. Ingbar, S. H. Simultaneous measurement of the iodide-concentrating and protein-binding capacities of the normal and hyperfunctioning human thyroid gland. J. clin. Endocr. 1955, 15, 238.

9. Thompson, H. L., Klugerman, M. R., and Truemper, J. A method for protein-bound iodide: The kinetics and use of controls in the ashing technique. J. Lab. clin. Med. 1956, 47, 149.

10. Light, F. Personal communication.

11. Smith, A. U., Emmens, C. W., and Parkes, A. S. Assay of thyroidal activity by a closed vessel technique. J. Endocr. 1947, 5, 186.

12. Barker, S. B. Determination of protein-bound iodide. J. biol. Chem. 1948, 173, 715.

13. Myant, N. B., Corbett, B. D., Honour, A. J., and Pochin, E. E. Distribution of radioiodide in man. Clin. Sci. 1950, 9, 405.

14. Harris, G. W. The reciprocal relationship between the thyroid and adrenocortical responses to stress in Ciba Foundation Colloquia on Endocrinology, The Human Adrenal Cortex. Boston, Little, Brown and Co., 1955, vol. VIII, p. 531.

15. Paschkis, K. E., Cantarow, A., Eberhard, T., and Boyle, D. Thyroid function in the alarm reaction. Proc. Soc. exp. Biol. (N. Y.) 1950, 73, 116.

16. Bogoroch, R., and Timiras, $P$. The response of the thyroid gland of the rat to severe stress. Endocrinology 1951, 49, 548.

17. Van Middlesworth, L., and Berry, M. M. Iodide metabolism during anoxia, nephrectomy, trauma, avitaminoses, and starvation in the rat. Amer. J. Physiol. 1951, 167, 576.

18. Ingbar, S. H., and Freinkel, N. ACTH, cortisone and the metabolism of iodine. Metabolism 1956, 5, 652. 